Instructions for authors, subscriptions and further details:

http://brac.hipatiapress.com

\title{
Asalto a la Comunicación. Una Redefinición del Fake como Práctica Artística Activista en la Sociedad de la Información
}

Vanni Brusadin 1

1) Universidad de Barcelona. España

Date of publication: October 3rd, 2015

Edition period: October 2015 - February 2015

To cite this article: Brusadin, V. (2015). Asalto a la comunicación. Una redefinición del fake como práctica artística activista en la sociedad de la información. Barcelona, Research, Art, Creation, 3(3), 233-255. doi: 10.17583/brac.2015.1637

To link this article: http://dx.doi.org/10.17583/brac.2015.1637

\section{PLEASE SCROLL DOWN FOR ARTICLE}

The terms and conditions of use, except where otherwise noted, are related to the Open Journal System and to Creative Commons Attribution License (CCBY). The indication must be expressly stated when necessary. 
BRAC - Barcelona Research Art Creation. Vol. 3 No. 3, October 2015, pp. 233-255

\section{An Assault to Communication. A Redefinition of Fake as an Artistic and Activist Practice in Information Society}

Vanni Brusadin

University of Barcelona

(Received: 10 July 2015; Accepted: 31 July 2015; Published: 3 October 2015)

\section{Abstract}

Fake is at the same time a generic term in Internet jargon and a strategy in artistic and activist interventions based on identity theft, hoax and other kinds of momentary confusion in a mass-mediated public sphere. In this article a more accurate definition of fake will be proposed according to three main principles: in the first place, the artistic and activist fake is not just a forgery, but a mechanism to subvert the functioning of discursive frames; secondly, it sets out to provoke symbolic conflict within a specific social and political context; and finally, its nature is intertwined with the historical and social conditions of use of communication technologies. This last issue will allow to sketch a new challenge: defining a possible evolution path of fake in the age of social media and big data.

Keywords: Fake, media, art, activism, internet 
BRAC - Barcelona Research Art Creation. Vol. 3 No. 3, October 2015, pp. 233-255

\title{
Asalto a la Comunicación. Una Redefinición del Fake como Práctica Artística Activista en la Sociedad de la Información
}

\author{
Vanni Brusadin \\ Universidad de Barcelona
}

(Recibido: 10 Julio 2015; Aceptado: 31 Julio 2015; Publicado: 3 Octubre 2015)

\section{Resumen}

El fake es al mismo tiempo un término genérico de la jerga de las redes y una estrategia de intervención artística y activista basada en la suplantación de identidad, la difusión de noticias falsas y otras formas de confusión momentánea en la esfera pública dominada por la comunicación de masas. En este artículo se propone una definición más rigurosa del término, centrada en tres cuestiones generales: el fake no como mera falsificación, sino como mecanismo de desactivación de marcos discursivos; en segundo lugar, su capacidad de provocar conflictos simbólicos en relación a un entorno social y político determinado; y finalmente su estrecha relación con el uso histórico y social de las tecnologías de comunicación. Este último punto permitirá esbozar un nuevo reto: entender la evolución de las prácticas del fake en la época de las redes sociales y de la "datificación" de la sociedad.

Palabras clave: Fake, media, arte, activismo, internet 


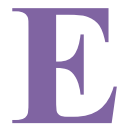

$\mathrm{n}$ la jerga de las redes fake es un término universalmente reconocido para indicar imágenes manipuladas digitalmente que, sin embargo, mantienen un alto nivel de verosimilitud lograda tergiversando de manera creíble fotografías de actualidad, o recontextualizando imágenes existentes, o bien imitando la apariencia gráfica de logotipos y marcas. A veces este término se utiliza para sintetizar todo un género audiovisual -el falso documental o mockumentary- basado en la construcción de la autenticidad a partir de la ficción ${ }^{1}$. En el lenguaje autóctono de las redes peer-to-peer es bastante frecuente hablar de fake en el caso de archivos que resultan no ser lo que su descripción indica y, en general, en las plataformas de redes sociales se usa para indicar falsas identidades de usuario y todo tipo de operaciones de manipulación de la información. Como ya se puede apreciar en esta muy sucinta introducción, el término se utiliza para hablar indistintamente o bien del resultado o bien de todo el proceso de falsificación y, a falta de una alternativa mejor, se suele utilizar el término inglés sin traducir, incluso en el vocabulario periodístico ${ }^{2}$.

En este artículo propondré una definición más rigurosa del término a partir de su uso en el arte activista para indicar prácticas de suplantación de identidad, difusión de noticias falsas y otras formas de generar interpretaciones contradictorias en una esfera pública dominada por los medios de comunicación de masas. En esos ámbitos fake muestra unos rastros comunes y persistentes: se trata de intervenciones conscientes en el tejido comunicativo en la intersección entre tecnologías, expectativas y hábitos sociales. El fake consiste en prácticas a menudo experimentales y con una intención crítica que, gracias a sus múltiples niveles de acción (tecnológica, imaginativa, social), son capaces de difuminar la frontera misma entre arte y activismo político.

El uso aparentemente distinto del término en el lenguaje cotidiano de las redes y en el ámbito artístico-activista en realidad esconde más de un punto en común: en ambos casos estamos hablando de prácticas basadas no tanto en el mero acto material de falsificación, sino en la puesta en marcha de pequeñas o grandes operaciones narrativas que podríamos definir como de no-ficción por no responder completamente ni a los criterios de la representación, ni a los del trabajo informativo, documentalista o activista ${ }^{3}$. En ambos casos también se aprecia una relación estrecha entre fake y tecnología, o mejor dicho, entre las condiciones tecnológicas y sociales de producción y circulación de la 
información. En tercer lugar, en ambos casos el fake está relacionado con algún tipo de conflicto simbólico en la vida cotidiana gracias a su capacidad para actuar como catalizador de acciones y reacciones en algún nivel de la compleja esfera pública contemporánea. Quiero defender la idea de que estos elementos básicos no solamente forman parte de una definición más precisa de fake, sino que también proporcionan claves de lectura fundamentales para interpretar una cuestión aún más importante: la transformación de estas prácticas creativas antes y después de la difusión masiva de las redes sociales.

\section{Elementos para una Definición del Fake "clásico"}

Entre los años cincuenta y sesenta, en la mayoría de los países del mundo se implantan costosas estructuras de producción y distribución de información, que curiosamente se suelen definir como networks (redes) aunque estén basadas en arquitecturas muy centralizadas. Se trata de sistemas eficientes, capaces de llegar rápidamente a los principales lugares públicos y a la mayoría de hogares gracias a "terminales" asequibles (aparatos radio, televisores, periódicos) y contenidos muy baratos o incluso gratuitos. Esta máquina organizada en un centro (arriba) y una red jerárquica (abajo) logró la difusión relativamente homogénea de ideas e imágenes gracias a las enormes economías de escala derivadas de la producción industrial de información y gracias también a su capacidad de repetir mecánicamente los mismos contenidos en miles o millones de terminales particulares.

En una época dominada por las estructuras productivas de la comunicación de masas el fake en mano de artistas y activistas se convirtió en un instrumento sorprendentemente efectivo para interferir con la propagación de la información según la lógica centralizada de la industria cultural o la propaganda de la época. La invención de falsas noticias sobre acontecimientos inexistentes (hoax), la tergiversación de mensajes mediáticos, la creación de identidades ficticias y nombres impropios (Deseriis, 2012), o incluso la suplantación de identidades existentes, se convirtieron en tácticas creativas para confundir tanto a los detentores del poder simbólico, como a los observadores distraídos, provocando en ambos reacciones imposibles de obtener con otras formas de crítica más directa o racional.

Si tomamos las campañas y bulos concebidos por los Yippies en Estados Unidos a finales de los años sesenta (Hoffman, 1968; Vale, 1988), la manipulación mediática del colectivo A/Traverso o del proyecto editorial- 
activista "Il Male" en Italia a finales de los años setenta (Sparagna, 2000; entrevistas inéditas del autor) o las acciones de artistas intervencionistas como Joey Skaggs o Alan Abel en Norte América entre los años cincuenta y ochenta (Abel, 1970; Vale 1988): podemos considerar sus intervenciones como formas experimentales de falsificación "desde abajo" que, cual virus capaz de desviar la fuerza de la maquinaria mediática y disparar la imaginación colectiva, fueron capaces de parasitar los medios de comunicación de masas y al mismo tiempo mostrar públicamente algunos aspectos normalmente invisibles de su funcionamiento. Naturalmente, los ejemplos mencionados se diferencian en muchos aspectos como por ejemplo sus objetivos estratégicos, su forma de actuar y desvelar el engaño y, por supuesto, su papel en un contexto cultural y político. Sin embargo, podemos decir que tanto los experimentos más explícitamente vinculados con movimientos sociales (como por ejemplo los Yippies o A/Traverso), como los experimentos artísticos más individuales y kamikaze (como las hazañas de Skaggs y Abel) tenían un objetivo común: desvelar los grandes y pequeños intereses particulares que alimentan la industria cultural y los modernos aparatos simbólicos de vigilancia, desde la censura o el control de los consumidores, hasta la distracción de masas y la construcción de mitos.

Cabe precisar que en el curso de la historia los gobiernos, u otras instituciones sociales como los grandes conglomerados mediáticos o las grandes marcas comerciales, han utilizado en muchas ocasiones la falsificación y otras técnicas de tergiversación de la información para sus objetivos. Sin embargo, mi investigación está enfocada en experimentos comunicativos llevados a cabo según una lógica fundamentalmente cooperativa que puede ser explícita en el caso de proyectos de activismo, o implícita en el caso de artistas que buscan activar la complicidad de una comunidad de observadores o participantes. En ningún caso su motivación principal es generar un beneficio económico o fortalecer instrumentos de control, sino mostrar la verdadera cara del poder y en última instancia fortalecer principios básicos como la emancipación y la necesidad de cuestionar jerarquías sociales inútiles e injustas.

Por tanto un criterio clave de una definición rigurosa de fake radica en el hecho que sus autores no buscan ventajas personales, ni ningún resultado concreto inmediato más allá de un atasco momentáneo en la normalidad de los discursos dominantes. Por esta razón el fake se configura necesariamente como una práctica pública y no importa si en algún momento estas operaciones tienen que recurrir al engaño y al secreto para poder ser llevadas a cabo; independientemente de cómo se desarrolle este juego de identidades, su 
objetivo último es cuestionar la normalidad de mecanismos comunicativos cotidianos y sobre todo de aquellas sutiles construcciones ideológicas que determinan nuestro horizonte imaginativo y nuestras expectativas. Por estas razones esta definición de fake como práctica pública conlleva inevitablemente una connotación crítica.

La dinámica entre imitación e invención original es otro aspecto importante. El fake implica camuflaje pero no puede pasar desapercibido; supone una imitación de formas reconocibles pero debe generar estupor o críticas, no simple ironía y aceptación complaciente. Entre los mensajes y expectativas generados por los medios de masas el fake busca grietas, contradicciones, conflictos latentes. Primero los hincha y luego los hace estallar, llevando a los interlocutores hacia una evaluación errónea de la situación para luego obligarles a ver sus reacciones como en un espejo. En esta estrategia comunicativa la confusión de las apariencias pone en funcionamiento un sofisticado juego en el cual la imitación (en cuanto suplantación, engaño, falsificación o plagio) y la invención original son caras inseparables de una misma moneda. El fake, en sus dos vertientes de engaño y de burla (prank), celebra la libertad de expresión a través de la invención desde abajo de "contra-historias", que suelen tener una característica peculiar: hablar de hechos o personajes que despiertan curiosidad, rozan el surrealismo y retan de manera sugerente nuestras expectativas sobre lo que consideramos plausible. De esta manera, estas historias de una realidad paralela buscan un enfrentamiento - si bien sutil, oblicuo - con la "realidad" de la información refrendada por las fuentes legítimas habituales. Se podría decir que el fake es la base de una suerte de "guerrilla narrativa".

En algunos casos la relación entre experimentación artística y activismo es directa, en otros es implícita y más sutil. Algunas operaciones son capaces de conectar con instancias políticas de relevancia colectiva; en otros casos, mantienen un estatus de acontecimiento único e irrepetible, cuya influencia se mide no tanto por su influencia sobre hábitos cotidianos o acontecimientos históricos, sino por la propagación irregular de un nuevo relato mítico y fuente de inspiración para nuevas acciones. En cualquier caso, incluso cuando las motivaciones son más claramente estéticas, es posible vislumbrar el potencial político de la alteración de la normalidad de la comunicación social. Y viceversa, hasta los proyectos con un perfil más activista funcionan gracias a un sofisticado trabajo simbólico y narrativo.

Las prácticas de fake parecen dialogar con todos estos aspectos dentro y fuera del mundo del arte y en diferentes contextos políticos e históricos. Por ahora, 
vale la pena recordar que algunos de estos proyectos atraviesan el campo del arte de forma táctica, otros entran en él sólo en el momento de su historización, otros lo usan como trampolín o bien como comunidad de colaboradores y cómplices. De todos modos, esta cuestión indica que las prácticas de juego de identidades, confusión y engaño han contribuido a forzar las definiciones establecidas de lo que se puede considerar legítimamente propio del campo artístico y en algunos casos ampliarlas hacia nuevos territorios.

\section{Una Cartografía de Conceptos Relevantes: Tres Ejes}

Algunos ámbitos de reflexión teórica han sido particularmente útiles a la hora de dar forma a la observación de un fenómeno aparentemente tan diverso como el fake mediático. Antes de pasar a mi propuesta de redefinición vale la pena esbozar una simple cartografía de conceptos útiles para situar algunas de las cuestiones mencionadas anteriormente.

El primer eje gira en torno a la definición de prácticas simbólicas de resistencia a los significados impuestos por el poder, adoptados de manera aparentemente irreflexiva por la mayoría en la vida cotidiana. Se trata de un ámbito sólo en apariencia alejado de los estudios artísticos tradicionales y mucho más cercano a los estudios culturales (en particular Hall 1981; Hebdige, 1979) y a su interés por prácticas de "guerrilla semiológica", una definición inspirada por algunas reflexiones del filósofo y crítico cultural Umberto Eco (1973). La metáfora bélica de la guerra de guerrillas dará lugar a todo un filón de análisis en torno al concepto de táctica y a su reformulación para adaptarla a la interpretación de la invención cotidiana como forma de sabotaje simbólico popular más o menos consciente. Los puntos de inflexión de estas reflexiones teórico-prácticas son la antropología de la vida cotidiana de Michel de Certeau (1980) y posteriormente el debate sobre los "medios tácticos" como forma de intervención artística y tecnológica en la época de la difusión social de las tecnologías digitales (Garcia \& Lovink, 1997; Kluitenberg, 2011). Retomando la idea de guerrilla en el ámbito de la comunicación pública, en los años noventa el periodista y crítico cultural Marc Dery acuña el término culture jamming (traducible como interferencia en la cultura) para describir prácticas híbridas y a menudo inclasificables de intervencionismo artístico, entre las cuales por ejemplo las burlas a la prensa o la modificación de vallas publicitarias (subvertising) (Dery, 1993). Pocos años después unos investigadores y activistas alemanes recopilarán decenas de prácticas y experimentos parecidos en un "Manual de la guerrilla de la 
comunicación" que recupera también los antecedentes europeos de este tipo de acciones creativas (Autonome a.f.r.i.k.a. gruppe, 1997).

El segundo eje aborda explícitamente la cuestión estética-política y la relación entre actividades de representación y formas de intervención directa en el tejido social y político. Podemos distinguir entre una vertiente más teórica, interesada en una redefinición de la autonomía de los procesos estéticos (lejos de definiciones ya obsoletas de autonomía del arte o vanguardias artísticas, como, por ejemplo, en Rancière, 2008; Léger, 2012), y corrientes de reflexión militante que unen la teoría política y estética con un análisis histórico y exploran la posibilidad de una relación más o menos directa entre trabajo simbólico y acción política (Guattari, 1992; Holmes, 2012; Raunig, 2010). Siguiendo un camino ligeramente distinto encontramos una serie de teóricos y activistas interesados en la cuestión de lo narrativo como detonador de formas de acción en respuesta al orden simbólico establecido, un ámbito en la frontera entre el estudio semiótico-antropológico de las narraciones míticas (de particular relevancia Barthes, 1957; Hyde, 1998) y aquellos estudios de comunicación social que miran más allá de la simple lógica práctica y comercial de la propaganda. Se trata de investigaciones sobre la posibilidad de generar interferencias en la realidad material de las relaciones sociales, económicas y políticas a partir de la imaginación y de todo tipo de mezcla entre ficción y no-ficción: desde de la noción de infrapolítica del antropólogo y politólogo J.C. Scott (1990) a la mitocracia del narratólogo y semiólogo Yves Citton (2010) o la dreampolitik o "política en la era de la fantasía" del teórico activista Stephen Duncombe (2007).

El tercer eje fundamental de esta cartografía conceptual se centra en reflexiones más recientes acerca de la relación entre arte, culturas digitales y la sociedad conectada. En las últimas décadas la confluencia entre arte y tecnologías se ha hecho cada vez más intensa. El tema principal que atraviesa todo el campo de los nuevos medios es la supuesta discontinuidad introducida por la explosión en el uso social de tecnologías digitales y en este sentido en esta investigación veremos contaminaciones, evoluciones y diferencias estructurales entre prácticas creativas digitales, pre-digitales y, por así decirlo, "post-digitales" (véanse por ejemplo Manovich, 2001; Blais \& Ippolito, 2006; Graham \& Cook, 2010; Quaranta, 2013; Bosma, 2011). En cualquier caso el análisis de casos de estudio más recientes no puede prescindir de la reflexión sobre las culturas de red y de los debates en torno a nociones como el folklore digital (Espenschied \& Lialina, 2009), la ingeniería crítica (véase, por ejemplo, Oliver, Savicic \& Vasiliev, 2011) o la condición “post-internet” (VV. 
AA., 2015), justo por mencionar algunos conceptos generales especialmente relevantes.

Como demuestran las autoras y autores mencionados, la reflexión sobre arte, tecnología, sociedad y representación es relevante también por su capacidad de metabolizar aportaciones teóricas procedentes de disciplinas más tradicionales y ensamblar las conclusiones más convincentes en aparatos conceptuales dinámicos y capaces de comprender la complejidad de la sociedad conectada. Elaborar instrumentos críticos híbridos ha sido la manera más eficaz de comprender un contexto en el cual el conocimiento es mediado estructuralmente por tecnologías cada vez más ubicuas, hasta el punto de difuminar la frontera entre lo analógico y lo digital, lo humano singular y lo algorítmico. El ámbito de los nuevos medios ha sido mucho más dinámico que otras disciplinas más asentadas a la hora de cruzar tradiciones artísticas no solamente con reflexiones y prácticas tecnológicas, sino también aportando un importante corpus de referencias a la reflexión filosófica, política e incluso socio-económica. En la teoría y el arte de los nuevos medios la heterogeneidad de enfoques, referencias y métodos no solamente no es un problema, sino que también se considera estructural y necesaria.

Esta multiplicidad de enfoques y de métodos permite apreciar las diferentes facetas de prácticas creativas que mezclan sensibilidad tecno-estética con inquietudes sociales y que tienen una relación bastante compleja con los mundos del arte. El fake se basa esencialmente en la intervención en el tejido comunicativo de la sociedad, pero esto no significa que se dejen de lado estrategias de representación, cuyo objetivo no es solamente documentar, sino construir narraciones con un valor "táctico" para desencadenar acciones y reacciones de otros actores sociales. Estas dinámicas atraviesan el territorio del arte, en algunos casos llegando a forzar sus fronteras o directamente desbordando hacia nuevos territorios.. En este sentido, la noción de "metodología artística" propuesta por Matthew Fuller (2008) parece especialmente relevante.

\section{Hipótesis Fundamentales para Redefinir la Noción y las Prácticas del Fake}

\section{1) El fake no es un fin en sí, sino un instrumento para desactivar marcos discursivos.}

En el origen de las operaciones artísticas y activistas en la estela del fake siempre encontraremos inevitablemente una acción de falsificación, sea la 
manipulación material de una imagen, la confusión entre datos reales y de ficción o la suplantación de una identidad existente. Aún así, estas formas de falsificación no constituyen un objetivo ni un fin en sí mismas, sino más bien son el punto de partida de una operación sobre el contexto. Tal como lo estamos describiendo aquí, el fake consiste en llevar a cabo un trabajo imperceptible de manipulación de un frame existente, donde por frames se entienden aquellos marcos interpretativos - en gran medida automáticos - que necesitamos para comprender una situación determinada, los actores que participan en ella y las expectativas que normalmente dicha situación debería generar. Me refiero aquí a una serie de nociones desarrolladas en etnometodología por Goffman (1974) y en lingüística y estudio de la comunicación política por Lakoff(2004). Efectivamente, podríamos decir que el fake es básicamente una operación de "trastorno del frame".

En este sentido, propongo una interpretación del fake como un conjunto de dispositivos comunicativos con diferentes niveles de complejidad que, lejos de ser simples operaciones formales estéticas, actúan en un contexto provocando contradicciones y reacciones. De hecho, los experimentos más interesantes en relación al fake parecen seguir dos caminos complementarios: por un lado, evitan los marcos reconocibles, que generan expectativas y estructuras de comprensión que podrían desactivar la fuerza de un mensaje; por otro lado, hacen visibles y luego quiebran públicamente aquellos marcos que tras un proceso de progresiva naturalización se han vuelto invisibles tanto en la vida diaria como en la comprensión de los medios de comunicación. En otras palabras un objeto en una galería de arte, o una performance donde está claramente marcada la línea entre lo que es actuación y lo que no, son de por sí fenómenos marginales en la perspectiva del fake, básicamente porque siguen operando desde el interior de un marco interpretativo reconocible (la galería de arte o un escenario teatral, no importa si formalizado o no). Sin embargo, esto no significa que el fake rompa con todo tipo de marco, frustrando continuamente las expectativas de observadores y participantes involuntarios. Al contrario, el hecho de que ciertos aspectos discursivos existan y sean reconocibles es crucial para el funcionamiento del fake. El objetivo de suplantar una identidad conocida o de desplegar una serie de astutos malentendidos es provocar un cortocircuito en la comprensión de la situación: inicialmente se perciben marcos discursivos reconocibles, pero en un momento determinado el mismo curso de los acontecimientos empezará a dar señales que desmienten las expectativas creadas o confirmadas; en muchos casos serán justamente los actores legítimos, en cuanto dueños de las 
identidades suplantadas o de las imágenes manipuladas, quienes no tendrán más remedio que frustrar estrepitosamente aquellas falsas expectativas para no perder del todo su autoridad simbólica. En realidad, hagan lo que hagan, su autoridad resultará igualmente afectada precisamente por la necesidad de reafirmar de manera explícita un frame original que surte sus efectos sólo cuando funciona sin ser objeto de reflexión.

$\mathrm{Al}$ respecto no se puede dejar de notar que hay un paralelismo fascinante entre la dinámica de construcción de un frame y el mecanismo ideológico. Con este término no me refiero tanto a la manipulación consciente de la información por razones de propaganda, sino más bien a formas de articulación de creencias o discursos míticos que de alguna manera apuntalan hábitos cotidianos y justifican comportamientos necesarios para la supervivencia de la comunidad y de nosotras en ella. La ideología en cierto sentido funciona a partir de marcos de reconocimiento de las situaciones, pero abarca un territorio de comportamientos y valores mucho más amplio del simple mecanismo del autoengaño (la falsa conciencia de origen marxista). De hecho, como sostiene Žižek (1989), la ideología es algo radicalmente opuesto e implica un comportamiento mucho más complejo y contradictorio. En una sociedad, sostiene Žižek ampliando las reflexiones de Lacan, existen creencias públicamente repudiadas y hábitos obscenos que pretendemos ignorar, pero en lugar de representar una amenaza para la comunidad y sus valores públicos, estas creencias y hábitos son precisamente lo que sostienen la comunidad. Por ejemplo, la explotación del medioambiente, el racismo hacia los migrantes o la defensa corporativa de la conducta de unos policías corruptos son comportamientos reprobados por la gran mayoría de la sociedad, sin embargo la verdadera amenaza para la comunidad viene de quienes toman demasiado en serio estos valores: "contaminar es malo, pero ¡hombre! sin el progreso volveríamos a la edad media"; "yo no soy racista, es que ellos son muchos y no hay trabajo para todos", "es verdad que las fuerzas de seguridad tienen que operar en la legalidad, pero ellos son unos violentos y los policías se tienen que defender". El mecanismo ideológico hace aceptable estas contradicciones entre valores públicos y unas excepciones que definimos obscenas en el sentido etimológico de la palabra: invisibles porque funcionan detrás del telón de fondo de nuestra actividad pública. A diferencia de la noción de ideología como superestructura, la narración ideológica según Žižek funciona según la fórmula de los "unknown knowns": "lo que no sabemos que en realidad sabemos perfectamente".

En este sentido, el fake puede llegar a subvertir el mecanismo que la 
sostiene. El fake es una operación que construye una concatenación de acontecimientos y la narración que se va produciendo (obviamente amplificada por los autores del fake) muestra cándidamente lo obsceno que sustenta los valores o las identidades públicamente aceptados. No se trata de denunciar la contradicción, puesto que la ideología sirve justamente para mostrarla como algo natural e incuestionable con argumentaciones racionales. Como recuerda Žižek a propósito del colectivo esloveno Laibach, la fuerza del engaño se halla precisamente en un "exceso de ortodoxia", en la adhesión literal y fanática a los valores públicos del enemigo simbólico (Žižek, 1993).

Las nociones de frame y de ideología permiten destacar la importancia de los aspectos de narración y ficción en este asalto a las dinámicas de la comunicación en la esfera pública, mostrando el aspecto aparentemente paradójico de la hipótesis: es gracias a un surplus de narración, y no a un trabajo de deconstrucción racional, que el fake acumula el potencial suficiente para contaminar aquellas narraciones que reafirman los frames o el propio mecanismo ideológico y que, en última instancia, sustentan el funcionamiento material de la sociedad, de la ideología del mercado o del Estado.

\section{2) El fake genera conflictos simbólicos que alimentan una esfera pública sana.}

Las operaciones que definimos bajo el paraguas del fake plantean una tensión entre interpretaciones disonantes con el objetivo de provocar desacuerdos, conflictos y reacciones y así volver a abrir un diálogo allí donde no había, se había atascado o había sido prohibido. El lugar natural de este conflicto es la esfera pública, aquel espacio simbólico donde se dan oportunidades de intercambio y confrontación entre distintas instancias sociales en el marco de una misma comunidad. A partir de la noción propuesta por Habermas (1962), se puede afirmar que la esfera pública es, en realidad, un espacio/tiempo abstracto más allá de su materialización en lugares y formas tangibles en el espacio físico, en los medios de comunicación, en las redes o en situaciones híbridas. La esfera pública no es un espacio fijo definido de una vez por todas, sino más bien una posibilidad que se da allí donde confluyen diferentes voces o reivindicaciones generando un diálogo cuya fuerza y vitalidad es inversamente proporcional a los intentos de control y censura. Fomentar la esfera pública como lugar de diálogo es una necesidad vital para cualquier comunidad sana y no autoritaria. No obstante, la esfera pública es un territorio inestable, sujeto a negociaciones, fenómenos de hegemonía o intentos de control. Puede incluso 
darse la ilusión de una esfera pública cuando el intercambio de opiniones o la visibilidad de diferentes opciones es simulada. Las aportaciones y críticas más interesantes a la noción de esfera pública son precisamente las que han introducido elementos de conflicto en la noción original (Kluge \& Negt, 1993; Fraser, 1990; Laclau \& Mouffe, 1985).

Laibach como grupo de artistas totalitarios, los Yes Men como portavoces de gobiernos y grandes corporaciones, "Český sen" como realización del sueño obsceno del consumidor reprimido de los países ex-comunistas son sólo algunos ejemplos de intervenciones artísticas y activistas que tienen una característica común: la intención de actuar en la esfera pública, tanto en sentido material como en sentido simbólico. El funcionamiento de las narraciones colectivas debe ser considerado como un capital en un proceso de constante reafirmación y verificación, un campo de batalla que a pesar de todos los intentos de control siempre ofrecerá una oportunidad para cuestionar, aunque sea por breves momentos, las jerarquías simbólicas dominantes. A través de un momento de confusión, el fake hace visibles hechos que de otra manera pasarían desapercibidos o que, si se enunciaran abiertamente, serían rechazados por principios, reprimidos o auto-reprimidos. A través de una confusión momentánea el fake refuerza un aspecto clave de la esfera pública "agonística" (Mouffe, 2007): el conflicto de posiciones como signo de vitalidad. Y lo hace con mayor eficacia cuando está en juego la existencia misma de la esfera pública, es decir: en aquellas situaciones en que determinados actores sociales intentan explícitamente cerrar, guiar o privatizar el diálogo, o bien cuando el control social es el resultado masivo y cada vez más automatizado de determinadas formas tecnológicas de relación entre personas.

\section{3) La transformación de la lógica del fake desde el contexto de la comunicación de masas hasta la época de las redes.}

Hasta el momento hemos visto que en la galaxia fake se mezclan invención estética, construcción de narrativas y comunicación social. El ingrediente clave que permite a esta mezcla asumir una dimensión colectiva es la capacidad de interactuar y a menudo infiltrar determinadas estructuras generales de reproducción de las ideas, como por ejemplo las rutinas productivas de la comunicación de masas, la publicidad, las relaciones públicas, la industria del entretenimiento o los protocolos técnicos y las dinámicas sociales de la comunicación en red. La reproducción del conocimiento en la sociedad de la información consiste en un complejo entramado de aparatos y canales de 
comunicación, formas culturales y relaciones sociales que contribuyen a crear ideas, difundir imágenes, legitimar comportamientos. Se trata de mecanismos colectivos que son al mismo tiempo sociales y tecnológicos y que ponen en funcionamiento formas de mediación a través de una más o menos articulada capa tecnológica. El fake desafía el funcionamiento "normal" e irreflexivo de esta mediación, creando opacidad donde esperábamos transparencia y doblez donde veíamos univocidad.

Sin embargo, en un contexto tecno-social en constante evolución las formas de mediación también varían y con ellas la redistribución del poder simbólico que define las expectativas y las narraciones dominantes. Por tanto las mismas operaciones que responden a la lógica del fake se encuentran inevitablemente en un proceso de doble inestabilidad: por un lado, la que radica en la naturaleza táctica del fake y en su necesidad de buscar grietas que permitan desafiar un poder simbólico aparentemente monolítico; por otro lado, la inestabilidad definida a partir de la cada vez más rápida evolución de los dispositivos tecnológicos y sociales de mediación.

La evolución de las prácticas artísticas y activistas en la época de las redes - respecto a contextos dominados por el control centralizado del Estado sobre los cuerpos de los ciudadanos o por los gatekeepers de la comunicación de masas - parece indicar un nuevo reto. El cambio de paradigma social y cultural provocado por las tecnologías digitales fomenta formas de intervención creativa que, si bien mantienen los elementos básicos de la lógica del fake, adoptan nuevos estilos y en parte nuevos parámetros sin abandonar del todo los antiguos, sino añadiendo una creciente complejidad.

Para comprender el alcance de estos cambios es necesario analizar el arco evolutivo que va desde la primera sociedad de la información hasta la actualidad. A grandes rasgos se pueden identificar tres fases con características coyunturales homogéneas: 1) el contexto de la producción industrial centralizada de comunicación de masas; 2) la primera etapa de la difusión social masiva de la tecnología digital y de la comunicación en red, y 3) la etapa de las redes sociales y de la comunicación de masas multidireccional. Propongo la hipótesis de que los fundamentos del fake como táctica artística y activista se definen precisamente en el contexto histórico que tiene como trasfondo el paradigma político-estético de la comunicación de masas. El fake se desarrolla entonces como respuesta (una de las muchas posibles) al control jerárquico de la sociedad a través de las estructuras jerárquicas de la producción industrial de información, como por ejemplo las grandes agencias de prensa, las "redes" radio-televisivas, las agencias de publicidad, etcétera. Se trata de 
sistemas con un alto nivel de centralización que operaban (y operan) a través de procesos industriales y a menudo mecanizados. Su funcionamiento se basa en la generación de flujos comunicativos unidireccionales y sus estructuras están poco interesadas en recibir feedback o poco preparadas para recibirlo.

En este contexto algunos artistas y activistas reflexionan sobre las posibilidades de infiltrar este nuevo sistema de consenso social para enseñar sus contradicciones o mostrar alternativas ajenas a la lógica estrictamente comercial. En cambio, en aquellos contextos históricos en que el control de la comunicación está en manos del estado, la complejidad aumenta y parece requerir respuestas aún más sofisticadas. Las diferencias en el contexto histórico-cultural afectan a las motivaciones, estilos y decisiones estratégicas de artistas y activistas. Sin embargo dentro del paradigma de la sociedad de la comunicación de masas se pueden identificar algunos elementos generales del fake que evolucionarán radicalmente sin desaparecer nunca del todo: por ejemplo, la construcción de personajes ficticios populares y reconocibles (como en el caso de Superbarrio Gómez en México a finales de los años 80 o los mismos Yes Men), la manipulación de las tecnologías de comunicación dominantes (los media como medio artístico, según una definición de Joey Skaggs), la lógica del exceso de literalidad o sobre-identificación (como por ejemplo los mencionados Laibach o "Il Male").

En los primeros años 90 se entrevén los primeros signos de una transformación que se consolidará a partir de la segunda mitad de la década y llegará hasta los primeros años del nuevo siglo. Podríamos considerar esta fase como la primera etapa social de la revolución digital, que empieza con la difusión global del World Wide Web y termina con la aparición de plataformas de social media o medios participativos basados en enormes cantidades de microcontenidos generados por millones de usuarios.

En los años 90 la difusión social de herramientas de creación y comunicación digital sienta las bases para una profunda evolución en las formas de pensar, trabajar y organizar la vida. Los conocimientos, los modelos organizativos y hasta los valores de las culturas informáticas desbordan las fronteras de las disciplinas técnicas y contaminan rápidamente fenómenos estéticos, sociales y políticos de todo tipo, dando lugar a nuevas formas de cultura digital y cultura de red. En este contexto, las herramientas de creación y comunicación digital disponibles para cada vez más gente (software de manipulación de imagen y sonido, redes peer-to-peer, almacenamiento barato) fomentan la lógica cultural de la copia y potencian la capacidad de expresión de actores sociales hasta entonces relegados a la marginalidad gracias a la autopublicación 
en las redes, los webrings, los blogs, etcétera. Emergen nuevas formas de creación popular que abarcan todo tipo de medios y de lenguajes, como el videoactivismo, la programación de software libre, nuevas formas de redes informativas autogestionadas, sin olvidar la intensísima experimentación con los videojuegos como nueva cultura popular. Las industrias de las noticias, del entretenimiento y de la publicidad empiezan a plantearse la necesidad de incluir la "comunidad" en sus modelos de negocio y exploran las primeras, tímidas formas de feedback, aunque en esta fase la cultura de masas reacciona todavía con lentitud y torpeza. Cierta euforia digital acaba contagiando mundos tan distintos como el empresarial o el activismo. En el primer caso hasta el punto de generar la burbuja especulativa de las empresas "punto com", que estalla alrededor del bienio 2000-01 y prepara el terreno para el "web 2.0". En el caso del activismo, los sectores más dinámicos acaban seducidos por la idea de una globalización "desde abajo" y las oportunidades para formas colectivas coordinadas de resistencia y acción.

En este contexto artistas y activistas experimentan con todo tipo de apropiación de capital simbólico ajeno. Adoptan masivamente el remix como lógica productiva apta para todo tipo de campos, gracias a herramientas que permiten realizar con relativamente poco esfuerzo y alta calidad mimética operaciones que en la época analógica sólo eran posibles gracias a complicados procedimientos de robo creativo. El aumento exponencial de la capacidad expresiva de individuos o colectivos permite desplegar narrativas cada vez más complejas que dan lugar a experimentos de creación de narrativas que desbordan los ámbitos del arte, de la literatura o de las reivindicaciones políticas. Algunos los llamarán experimentos "mitopoéticos" porque las intervenciones creativas radicales en este nuevo tejido conectivo llegan hasta la construcción de relatos que recuerdan la función original de los mitos: narraciones con valor colectivo que a través de elementos de ficción mezclados con referencias reales explican la historia y los futuros retos de una comunidad. En estos experimentos de narraciones míticas "desde abajo" emergen identidades ficticias con efectos reales como es el caso del proyecto activista Luther Blissett, que se propone nada menos que redefinir el papel del héroe contracultural en la época de las redes (Deseriis, 2010). Schlingensief, RTMark, los Yes Men, Ztohoven, 0100101110101101, Serpica Naro, entre muchos otros, protagonizan burlas clamorosas que se convierten rápidamente en cuentos míticos de un nuevo underground capaz de infiltrar el mainstream. A pesar de utilizar nuevos canales y de tener público y ambiciones cada vez más globales, la lógica subyacente del fake en la primera etapa de las 
culturas de red es una ampliación de la misma lógica del fake en la época de la comunicación de masas: estrategias de secuestro de la atención, trampas para los gatekeepers y sabotaje de las poderosas máquinas de construcción del consenso. Sin embargo, la magnitud y el impacto de los resultados son mucho más grandes, gracias también a la capacidad multiplicadora de las herramientas de comunicación y de documentación en mano de actores sociales independientes.

La emergencia de la lógica colaborativa de las redes y su difusión en sectores de público totalmente transversales entre 2007 y 2010 son el punto de inflexión que permite abrir una fase radicalmente nueva. En este nuevo contexto todas las dinámicas de la vida en común se transforman de manera profunda y entre ellas también el fake herético y rebelde. En la época de la conexión ubicua e instantánea, de Google y Wikipedia como fuentes indisputables de legitimidad y veracidad, hay objetivamente menos margen de maniobra para operaciones de pura y simple falsificación. Aún así, el espíritu original parece calar en nuevas tácticas e inventos.

El gigantesco dispositivo tecno-social que llamamos redes sociales es el resultado de diferentes factores que se han desarrollado en paralelo. En primer lugar, la evolución técnica de la capacidad de procesamiento de datos, de los lenguajes de programación, de la gestión de metadatos y de los algoritmos de indexación de los contenidos en red producen buscadores sofisticados, contenidos dinámicos y perfiles de usuarios que dejan un rastro indeleble.

El segundo factor es de tipo económico. La necesidad de sostener económicamente servicios cada vez más complejos sustituye gradualmente la espontaneidad y la auto-organización como motor de la actividad en las redes. La razón es sencilla: un modelo basado en la auto-organización es más costoso en términos de tiempo y recursos y desde luego costaría demasiado adaptarlo al ingreso de millones de usuarios acostumbrados a la idea de consumo fácil y de interfaces estandarizadas típicas del paradigma usuarioservicio de masas. Tras unos años de experimentación (básicamente la época del web "1.0"), se fue afinando un modelo de rentabilidad económica de nueva generación, basado no en la publicidad pasiva, sino en la venta masiva de datos de usuarios a intermediarios. A su vez, ellos los venderían a productores de bienes comerciales y a intermediarios financieros de los cuales los mismos productores industriales de bienes y servicios dependen cada vez más para su financiación.

El tercer factor que explica la evolución del paradigma de los social media radica en un aspecto contradictorio del desarrollo de las redes como 
espacio público y privado. La democratización masiva de la herramientas de comunicación y cooperación afecta al front end de la red, mientras que sus infraestructuras hardware y software entran en un proceso de constante recentralización y control debido tanto a razones económicas como al interés estratégico-militar de los estados nacionales (y, en particular, de algunas superpotencias mundiales). El resultado es la coexistencia de aspectos dramáticamente opuestos: el aumento exponencial de las posibilidades de cooperación se acompaña con la concentración de los recursos y de la riqueza material; la participación libre y voluntaria coexiste con unos mecanismos muy concretos de vigilancia y de autovigilancia masiva; la multiplicación de las oportunidades de libre expresión y crítica se dan en un contexto de ruido y anomia crecientes.

Esta evolución tecnológica, cultural y política trae consigo unos elementos que parecen desafiar los fundamentos del fake "clásico", nacido en el contexto de la primera sociedad de la información y basado en la creación de identidades o falsos acontecimientos. Por ejemplo, es razonable pensar que la rapidez y eficacia de sistemas de búsqueda y comprobación de datos hacen inviable y efímera la invención de identidades o acontecimientos ficticios. La "datificación" de todo tipo de información personal por razones de control y explotación económica refuerza la construcción de identidades fijas y reconocibles, construida en parte sobre la identidad civil otorgada por el estado, y en otra parte muy significativa sobre perfiles de usuario compuestos de múltiples fragmentos controlados por intermediarios privados o extraestatales opacos. También cabe recordar que la complejidad de las redes hace que la reproducción de un relato o una información sea cada vez más difícil de guiar y alcance un público cada vez más aleatorio (o controlado por algoritmos propietarios cuyo funcionamiento exacto se desconoce). Y por último un aspecto anecdótico, aunque no necesariamente menos relevante: el éxito de proyectos que han hecho de la falsa noticia un género extremadamente popular y reconocible en la red, desde el marketing viral hasta medios de información paródicos como "El Mundo Today" en España.

Sin embargo, otros factores parecen abrir nuevas posibilidades. El reto consiste precisamente en trazar líneas que indiquen la evolución radical del espíritu del fake "tradicional" en la era de Google, de Wikipedia, de las ciudades inteligentes o de los memes. Por ejemplo la confusión como arma de subversión simbólica puede llegar a convertirse en una estrategia distribuida globalmente entre diferentes actores o miniaturizada en cientos de microintervenciones en las redes sociales, reclamando la necesidad de una narración 
que las haga visibles y que cree memoria en un contexto que fagocita y olvida tan rápidamente como crea. La misma diseminación desordenada de imágenes y la fragmentación de los oyentes en públicos accidentales plantean nuevas formas de intervención en las cuales la ingeniería inversa y el juego de las apariencias siguen siendo estrategias viables y efectivas para todos los actores creativos - artistas, activistas o outsiders - que quieran reivindicar la diversidad y la libertad que la revolución digital había prometido y que no obstante la utopía de la eficiencia económica y el control político en las redes están de facto aplastando.

\title{
Principales referencias web sobre los proyectos mencionados
}

\begin{abstract}
Alan Abel: la mejor documentación de sus acciones es su página web http:// www.alanabel.com/y el documental "Abel Raises Cain" (J. Abel \& J. Hockett, EE.UU. - 2009)
\end{abstract}

Joey Skaggs: documentación de sus acciones en http://joeyskaggs.com/

Laibach: página web de la banda con documentación del proyecto "Laibach Kunst" en http://www.laibach.org/

Superbarrio Gómez: entre las más completas fuentes de información directa las dos charlas realizadas en el marco del festival "The Influencers" (del cual soy director), la documentación vídeo se encuentra en http://theinfluencers. org/superbarrio

Luther Blissett: el archivo bastante completo de todos los materiales textuales se encuentra http://lutherblissett.net/

0100101110101101.ORG: documentación del proyecto en http://0100101110101101.org/

®TMark: documentación del proyecto en http://rtmark.com/

The Yes Men: documentación del proyecto en http:/theyesmen.org/ y http:// yeslab.org/

Christoph Schlingensief: la documentación de toda su actividad incluyendo las obras teatrales se encuentra en http://www.schlingensief.com/, en la sección "Performance" se encuentran referencias a sus proyectos más directamente relacionados con el fake: http://www.schlingensief.com/aktion_eng.php

Český sen: documentación del proyecto en http://www.ceskysen.cz/index. php?load=english

Ztohoven: documentación del proyecto en http://www.ztohoven. $\mathrm{com} /$ ?lang=en 
Serpica Naro: la historia de la burla y de cómo nació el proyecto se encuentra en http:/www.serpicanaro.com/serpica-story/serpica-naro-il-media-sociale (en italiano)

\section{Notas}

${ }^{1}$ Véase por ejemplo Juhasz \& Lerner, 2006.

2 Para un ejemplo reciente en español véase “¿Este hielo transparente es un “fake’?” en las noticias de Radio Televisión Nacional de España http:/www.rtve.es/noticias/20150113/estehielo-transparente-fake/1081890.shtml (consultado el 30/05/2015).

${ }^{3}$ Mi uso de la noción de "no ficción" remite explícitamente a la correspondiente categoría literaria, utilizada para describir relatos que mezclan aspectos formales de la novela o el punto de vista subjetivo del narrador con los contenidos, datos y referencias típicas de la objetividad periodística.

\section{Referencias}

Abel, A. (1970). The Confessions of a Hoaxer. New York: Macmillan. Autonome a.f.r.i.k.a.-gruppe, Luther Blissett, Sonja Brünzels (1997).

Handbuch der Kommunikationsguerilla. Vorwort zur vierten Auflage (trad. cast. Manual de guerrilla de la comunicación. (2000) Barcelona: Virus).

Barthes, R. (1957). Mythologies. Paris: Seuil.

Blais, J., \& Ippolito, J. (2006). At the Edge of Art. London: Thames \& Hudson.

Bosma, J. (2011). Nettitudes: Let's Talk Net Art. Rotterdam: nai010 publishers.

Citton, Y. (2010). Mythocratie. Storytelling et imaginaire de gauche. Paris: Éditions Amsterdam.

De Certeau, M. (1980). L'Invention du quotidien, 1. : Arts de faire. Paris: Gallimard.

Dery, M. (1993). Culture Jamming: Hacking, Slashing, and Sniping in the Empire of Signs. NJ: Open Magazine Pamphlet Series.

Deseriis, M. (2010). Lots of Money Because I am Many: The Luther Blissett Project and the Multiple-Use Name Strategy. En Begum O. Firat \& Aylin Kuryel (Eds.), Cultural Activism: Practices, Dilemmas and 
Possibilities, Amsterdam: Rodopi.

Deseriis, M. (2012). Improper names: Collective pseudonyms and multipleuse names as minor processes of subjectivation. En Subjectivity (2012) $5,140-160$.

Duncombe, S. (2007). Dream: Re-imagining Progressive Politics in an Age of Fantasy. New York: The New Press.

Eco, U. (1973 - original del 1967). Per una guerriglia semiologica. En II costume di casa. Milano: Bompiani.

Espenschied, D., \& Lialina, O. (2009). Digital Folklore. Stuttgart: Merz \& Solitude.

Fraser, N. (1990). Rethinking the Public Sphere: A Contribution to the

Critique of Actually Existing Democracy. Social Text, 25(26), 56-80.

Fuller, M. (2008). Art methodologies in Media Ecology. En S. O'Sullivan

$\&$ S. Zepke (Eds.), Deleuze, Guattari and the Production of the New.

Bloomsbury Publishing. Recuperado el 30 de mayo de 2015, a partir de http://www.spc.org/fuller/texts/art-methodologies-in-media-ecology/

Garcia, D., \& Lovink, G. (1997). The ABC of Tactical Media. Recuperado el 30 de mayo de 2015, a partir de http://amsterdam.nettime.org/ListsArchives/nettime-1-9705/msg00096.html

Goffman, E. (1974). Frame Analysis. London: Harper and Row

Graham, B. \& Cook, S. (2010). Rethinking Curating: Art after New Media.

Cambridge, MA: The MIT Press.

Guattari, F. (1992). Chaosmose. Paris: Galilée.

Habermas, J. (1989). The Structural Transformation of the Public Sphere:

An Inquiry into a category of Bourgeois Society, Cambridge: Polity.

Traducción de Habermas, J. (1962). Strukturwandel der öffentlichkeit.

Luchterhand Neuwied.

Hall, S. (1981). Notes on Deconstructing the Popular. En People's History and Socialist Theory. London: Routledge.

Hebdige, D. (1979). Subculture: The Meaning of Style. London: Routledge. Hoffman, A. (1968). Revolution For the Hell of It. New York: Dial Press.

Holmes, B. (2012). The Fourfold Matrix of Contemporary Social

Movements. En Thompson, N. (Ed.), Living as Form. Cambridge, MA:

The MIT Press.

Hyde, L. (1998). Trickster Makes This World: Mischief, Myth, and Art. New York: Farrar, Straus \& Giroux.

Juhasz, A., \& Lerner, J. (Eds.). (2006). $F$ is for phony: fake documentary and truth's undoing. Minneapolis: University of Minnesota Press. 
Kluge, A. \& Negt, O. (1993), Public sphere and experience : toward an analysis of the bourgeois and proletarian public sphere, Minneapolis: University of Minnesota Press

Kluitenberg, E. (2011) Legacies of Tactical Media, Amsterdam: Institute of Network Cultures.

Laclau, E. \& Mouffe, C. (1985). Hegemony and Socialist Strategy. Towards a Radical Democratic Politics. London: Verso.

Lakoff, G. (2004). Don't Think of an Elephant: Know Your Values and Frame the Debate. Hartford, VT: Chelsea Green Publishing.

Léger, M. J. (2012). Brave New Avant Garde. Essays on Contemporary Art and Politics. London: Zero Books.

Manovich, L. (2001). Post-media Aesthetics. Recuperado el 30 de mayo de 2015 de http://manovich.net/index.php/projects/post-media-aesthetics Mouffe, C. (2007), Artistic Activism and Agonistic Places. En Art \& Research, Vol. 1, No. 2 Summer 2007.

Oliver, J., Savičić, G., \& Vasiliev, D. (2011, actualizado 2015). The Critical Engineering Manifesto. Recuperado el 30 de mayo de 2015 de https:// www.criticalengineering.org/

Quaranta, D. (2013). Beyond New Media Art. Brescia: Link Editions. Rancière, J. (2008) Le spectateur émancipé. Paris: La Fabrique. Raunig, G. (2010). A Thousand Machines. A Concise Philosophy of the Machine as Social Movement. Cambridge, MA: The MIT Press. Scott, J.C. (1990). The Infrapolitics of Subordinate Groups en Domination and the Arts of Resistance: Hidden Transcripts. New Haven: Yale UP. Sparagna, V. (2000). Falsi da ridere. Roma: Malatempora. Vale, V. (1988). RE/Search \#11: Pranks. San Francisco: RE/Search Publications.

VV.AA. (2015). The Internet Does Not Exist. Berlin: Sternberg Press. Žižek, S. (1989). The Sublime Object of Ideology. London: Verso Books. Žižek, S. (1993). Why are Laibach and NSK not fascists? en M'ars, vol. 5, n. 3-4. 
Vanni Brusadin: Profesor Asociado en el Departamento de Diseño e Imagen de la Universidad de Barcelona.

Contact Address: Facultad de Bellas Artes. Universidad de Barcelona. Departamento de Diseño e Imagen. c/ Pau Gargallo 4, 08028 Barcelona (España).

E-mail address: brusadin@ub.edu 